\title{
Orthometric Corrections Using Gridded Gravity Data Derived from Digital Elevation Model
}

\author{
Hong Sool Lee, Kwang Bae Kim, ${ }^{*}$ Chang Uk Woo, and Hong Sik Yun \\ 1Department of Civil, Architectural, and Environmental System Engineering, Sungkyunkwan University, \\ 2066 Seobu-ro, Jangan-gu, Suwon, Gyeonggi-do 16419, Republic of Korea
}

(Received September 27, 2021; accepted December 2, 2021; online published January 5, 2022)

Keywords: gridded gravity data, gravity, height, digital elevation model, orthometric correction

In this study, gridded gravity data (GGD) were generated by using the correlation between gravity and the height extracted from a high-resolution digital elevation model (DEM) in an area where the national control points where gravity was measured are not densely distributed. Comparison of the measured gravity and the gravity generated by using GGD, which is produced by the linear regression analysis of the height extracted from DEM at the national control points, revealed that the accuracy of GGD is about $33 \mathrm{mGal}$. The difference is very small at about 4 and $5 \mathrm{~mm}$, when comparing the orthometric correction for each section and the cumulative orthometric correction calculated using the gravity interpolated from GGD with the results calculated from the measured gravity, respectively. Thus, it is considered that the orthometric correction can be effectively calculated by using the gravity interpolated from GGD at the points where there are no measured gravity data. If the gravity distribution measured at national control points becomes dense, it is expected to further improve the accuracy of the gravity interpolated from the GGD, which is generated by using the linear correlation between the gravity and the height extracted from high-resolution DEM.

\section{Introduction}

The height of any station on Earth is generally determined by calculating the height difference between two stations through leveling and adding the height of the station with a known height to that difference. Since height is a function in relation with gravity, it can be divided into dynamic height, normal height, and orthometric height. Dynamic height is obtained by dividing the geopotential number by a constant gravity value, $\gamma_{0}$, chosen as the value of normal gravity at $45^{\circ}$ latitude. Normal height is calculated by dividing the geopotential number by the mean normal gravity along the plumb line. Orthometric height is the distance from the geoid to Earth's surface along the plumb line.$^{(1,2)}$ To accurately determine the height of a station, we should consider both the geometric height difference calculated by leveling and the physical height difference calculated according to the difference in gravitational potential.

*Corresponding author: e-mail: kbkim929@skku.edu

https://doi.org/10.18494/SAM.2022.3665 
As shown in Eq. (1), the orthometric height $(H)$ can be calculated from the mean gravity $(\bar{g})$ and the geopotential number $(C)$ calculated along the plumb line between the geoid and the surface station.

$$
H=C / \bar{g}
$$

Alternatively, it can be obtained by calculating an orthometric correction by using data obtained from Global Navigation Satellite System (GNSS) surveying, leveling, and gravity surveying. In flat areas, there is little change in height caused when the gravity is affected by a change in density within Earth. In mountainous areas, the horizontal planes at each point where the leveling was performed are not parallel to each other. Such a change in gravity should be considered by using the gravity value measured at each station. Therefore, to accurately determine the height of an unknown point, not only the height difference calculated by leveling, but also the orthometric correction caused by a difference in gravity should be considered.

In Korea, $70 \%$ of the land is composed of mountainous terrain, which is very uneven. In particular, the size of the orthometric correction cannot be overlooked at the leveling line crossing the mountainous areas extending in the north-south direction. By considering the orthometric correction reflecting the effect of gravity, the orthometric height must be calculated. However, in the section where leveling was performed, considering the normal orthometric correction calculated from the latitude and the average height of the leveling line, the normal orthometric height system has been maintained to this day. ${ }^{(3)}$

The formula for calculating the orthometric correction has been proposed by several geodesists. After the basic formula to obtain the orthometric correction was proposed, ${ }^{(1)}$ a traditional formula for calculating it using the actual gravity was proposed. ${ }^{(4)}$ A formula for calculating the orthometric correction using the Bouguer gravity anomaly (BGA) was proposed, ${ }^{(5)}$ as well as a modified formula for calculating the BGA in the orthometric correction formula. ${ }^{(6)}$ The orthometric correction formula was partially improved and Taiwan's orthometric correction was used for the calculation. ${ }^{(7,8)}$ The advantages and disadvantages of various height systems and their practical applications are summarized in Ref. 9.

To perform an orthometric height conversion, it is necessary to review the previous studies first. It was reported that an orthometric correction of more than $10 \mathrm{~cm}$ was calculated at an adjacent benchmark with a height of more than 3,000 m using the newly proposed orthometric correction calculation formula in order to systematically calculate the orthometric correction in Taiwan. ${ }^{(7)}$ In the Italian leveling network that crosses the Alps, the orthometric correction difference was calculated between the actual measured gravity value and the gravity value extracted from the Earth Gravitational Model 2008 (EGM2008). It was reported that the orthometric correction differences between the observed gravity and the predicted gravity from EGM2008 were 0.295 and $0.459 \mathrm{~m}$ in the two leveling lines AF and 155 , respectively. ${ }^{(10)}$ In addition, several studies to determine the rigorous orthometric heights and the practical possibility of replacing the use of Helmert orthometric heights with normal orthometric heights were carried out. ${ }^{(11-13)}$ 
In Korea, a precision calculation of orthometric height by orthometric correction was performed mainly through leveling and gravity surveying data measured at national control points. ${ }^{(14,15)}$ Various orthometric corrections were calculated in mountainous areas by using the existing gravity data or actual measured gravity data, and then the orthometric height was determined. ${ }^{(16-19)}$ The orthometric correction based on gravity data was calculated mainly for orthometric height determination in various study areas, including Seorak Mountain and Jiri Mountain. To reflect the effect of gravity due to the change in the height of the terrain, it is necessary to convert the normal orthometric height system to the orthometric height system.

Existing studies focused mainly on the calculation of the orthometric correction and orthometric height by using the measured gravity values. However, in this study, we aim to verify the accuracy of the gridded gravity data (GGD) calculated by using the correlation between height and gravity. In addition, by using the gravity value interpolated from GGD and comparing it with the orthometric correction calculated with the measured gravity value, we evaluated a change in height difference according to the undulation of the terrain in mountainous areas.

As shown in the study flow chart in Fig. 1, this study was conducted in the following order. First, after resampling from $5 \mathrm{~m}$ digital elevation model (DEM) to 5" DEM, the height was extracted from the national control points (benchmarks, triangulation points, and unified control points). Second, the gravity value was estimated through a linear regression analysis of the measured gravity and the height extracted from the national control points. Third, this estimated gravity value was used to generate GGD in the study area. Fourth, this GGD were interpolated into the national control points, and the difference between the interpolated gravity and the measured gravity was compared and analyzed. Thus, the accuracy of the GGD was evaluated. Finally, the orthometric correction calculated by using the gravity value interpolated from GGD

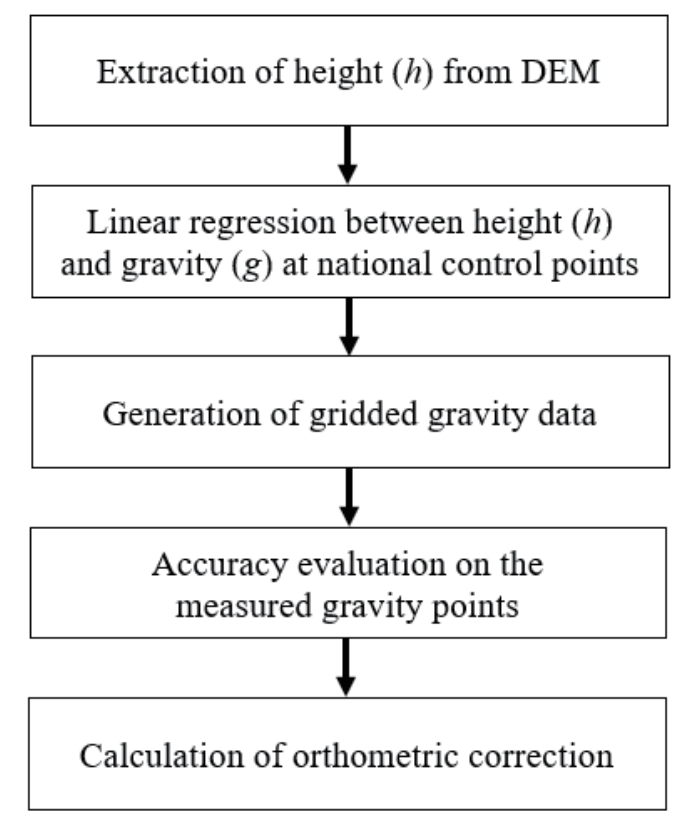

Fig. 1. Flow chart of the study. 
at the national control points of the actual leveling line was compared with the orthometric correction calculated from the measured gravity.

\section{Materials and Methods}

\subsection{Study area and data}

On the basis of the high correlation between the height data and gravity data in mountainous areas, it is possible to generate GGD by using the gravity estimated by linear regression analysis and to estimate the gravity value at an arbitrary station where there are no gravity data. The study area $\left(127.50^{\circ}-128.75^{\circ} \mathrm{E}, 37.25^{\circ}-38.25^{\circ} \mathrm{N}\right)$ for generating GGD includes mountainous areas with a height of $800 \mathrm{~m}$ or more in the Baekdudaegan Mountains in the eastern part of the Korean Peninsula, as indicated by the red rectangle in Fig. 2. As shown in Fig. 3, the gravity data measured in the study area indicated by the red square in Fig. 2 obtained a total of 1025 points in the first-order and second-order benchmarks (indicated by black and red squares) among the national control points. To ensure the distribution and homogeneity of the national control points where gravity was measured, we additionally used the gravity data measured at 538 triangulation points (indicated by black triangles) in the Seorak Mountain and Taebaek Mountain regions in 2011, 2012, and 2015 by the National Geographic Information Institute(NGII, https:/www.ngii. go.kr/kor/main.do), as well as the gravity data measured at 281 unified control points (indicated

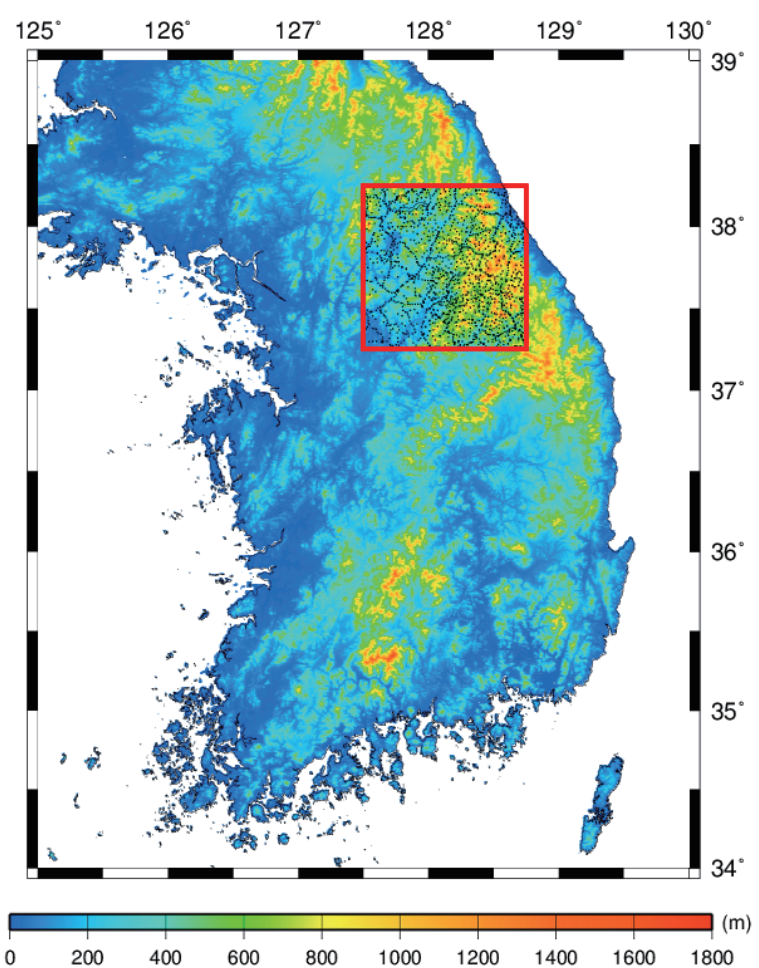

Fig. 2. (Color online) Location of study area and national control points where gravity was measured. 


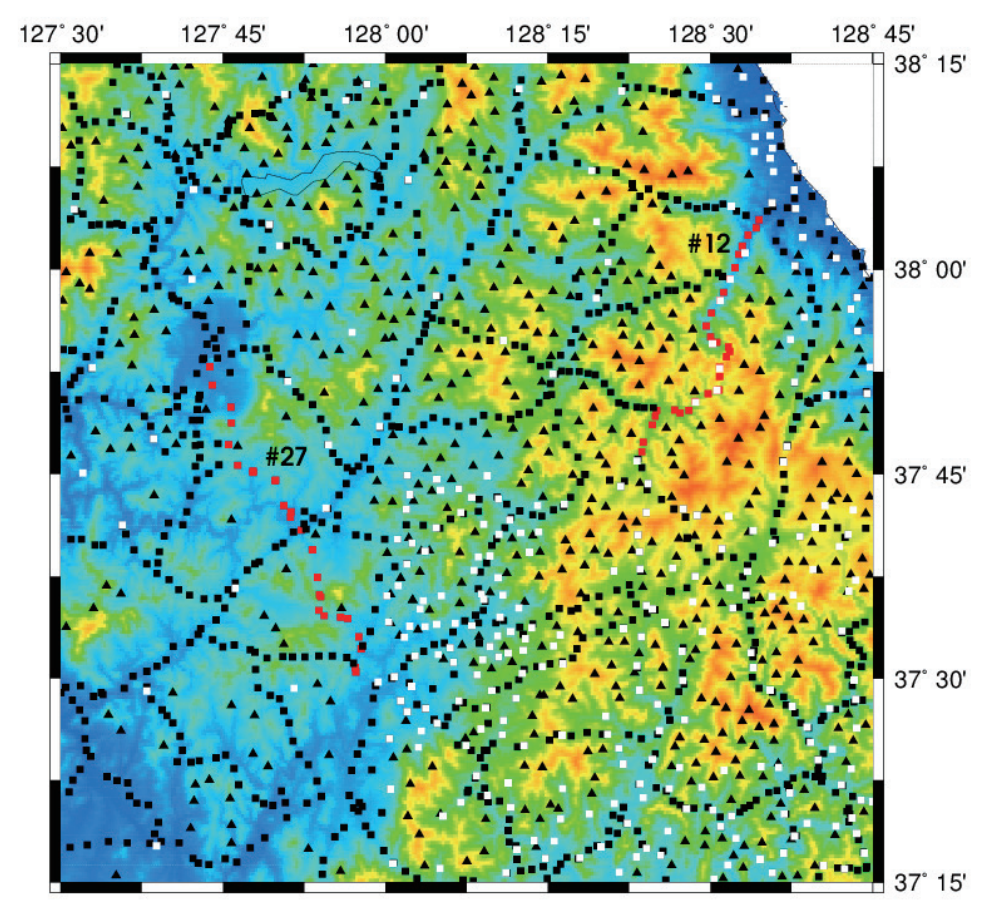

Fig. 3. (Color online) Location of measured gravity in the study area.

by white squares) in the Gangwon region in 2015 and 2018. In this study, the gravity data measured at a total of 1844 national control points (benchmarks, triangulation points, and unified control points) were used.

\subsection{Calculation of orthometric correction}

Orthometric height can be obtained by leveling. However, the height difference $\left(=H_{B}-H_{A}\right)$ between two stations, A and B, does not coincide with the sum of geometric height differences $\left(\Delta n_{A B}\right)$ obtained by leveling between stations $\mathrm{A}$ and $\mathrm{B}$. Therefore, to obtain an accurate height difference between the two stations, it is necessary to calculate the orthometric correction $\left(O C_{A B}\right)$ between them as shown in Eq. (2):

$$
\Delta H_{A B}=H_{B}-H_{A}=\Delta n_{A B}+O C_{A B} .
$$

Since the gravity due to the change in Earth's internal density at stations A and B can be expressed as a linear function with the height, the orthometric correction $\left(O C_{A B}\right)$ can be calculated by using various equations. ${ }^{(1,4,5,7,8)}$ Among the five equations in this study used to calculate the orthometric correction, the Heiskanen and Moritz formula was used as shown in Eq. (3) in consideration of the change in the gravity value at the two stations: 


$$
O C_{A B}=\sum_{A}^{B} \frac{g-\gamma_{0}}{\gamma_{0}} d H+\frac{\bar{g}_{A}-\gamma_{0}}{\gamma_{0}} H_{A}-\frac{\bar{g}_{B}-\gamma_{0}}{\gamma_{0}} H_{B},
$$

where $\gamma_{0}$ is the normal gravity at any latitude (typically $45^{\circ} \mathrm{N}$ or $45^{\circ} \mathrm{S}$ ), $d H$ is the height difference between stations A and B, $g$ is the average of the gravity values measured at stations A and B (= $\left.\left(g_{A}+g_{B}\right) / 2\right), \bar{g}_{A}$ are $\bar{g}_{B}$ the mean gravity on the plumb line between the geoid and Earth's surface $\left(\bar{g}_{A}=g_{A}+0.0424 H_{A}, \bar{g}_{B}=g_{B}+0.0424 H_{B}\right)$, and $H_{A}$ and $H_{B}$ are the heights of stations A and $\mathrm{B}$, respectively.

\section{Results and Discussion}

\subsection{Estimation of GGD}

In this study, 5" (about $150 \mathrm{~m}$ ) gridded height data were extracted in the study area as shown in Fig. 3 by resampling a DEM with $5 \mathrm{~m}$ spatial resolution using the nearest neighbor method of ArcGIS Pro S/W (https://www.esri.com/). The study area includes flat land, hilly land, and mountainous area. Height interpolated from 5" gridded height data was calculated for a total of 1844 national control points (benchmarks, triangulation points, and unified control points) in the study area in order to generate GGD using the high correlation between the measured gravity and the high-resolution height data. When the extracted 5" gridded height data are interpolated to the national control points within the study area, the minimum height is $2.141 \mathrm{~m}$ and the maximum height is $1680.821 \mathrm{~m}$. As shown in Fig. 4, the gravity data at the 1844 national control points range from 979610.715 to $980032.053 \mathrm{mGal}$. In this study, the gravity was calculated by using the linear regression equation derived from the linear correlation between the measured gravity and the height extracted from a high-resolution DEM in an area where the national control points where gravity was measured are not densely distributed. The root mean square error (RMSE) of the estimated gravity from the linear regression is $33.18 \mathrm{mGal}$.

The coefficient of determination $R^{2}$ and the coefficient of the linear regression equation were calculated in order to determine the correlation between the two data through the linear regression analysis of the measured gravity at 1844 national control points and the height interpolated from the 5" gridded height data. As shown in Fig. 4, $R^{2}$ between the height and gravity at 1844 national control points is 0.8043 , thereby indicating a high correlation between the two data. As shown in Fig. 4, when the height is small, the measured gravity is large, and conversely, when the height is large, the measured gravity is small. In addition, the coefficient of the linear regression equation can be expressed as Gravity $=-0.2215 \times$ Height +979960.9843 . The height parameter estimation of the linear regression is considered to be reliable because the $\mathrm{p}$-value of the F-statistic is significant within $1 \%$.

The linear regression equation (indicated by the red line in Fig. 4) was used to estimate the gravity values for 1025 benchmarks (indicated by black and red rectangles), 538 triangulation points (indicated by black triangles), and 281 unified control points (indicated by white rectangles) among the national control points, as shown in Fig. 3 in this study. On the basis of 


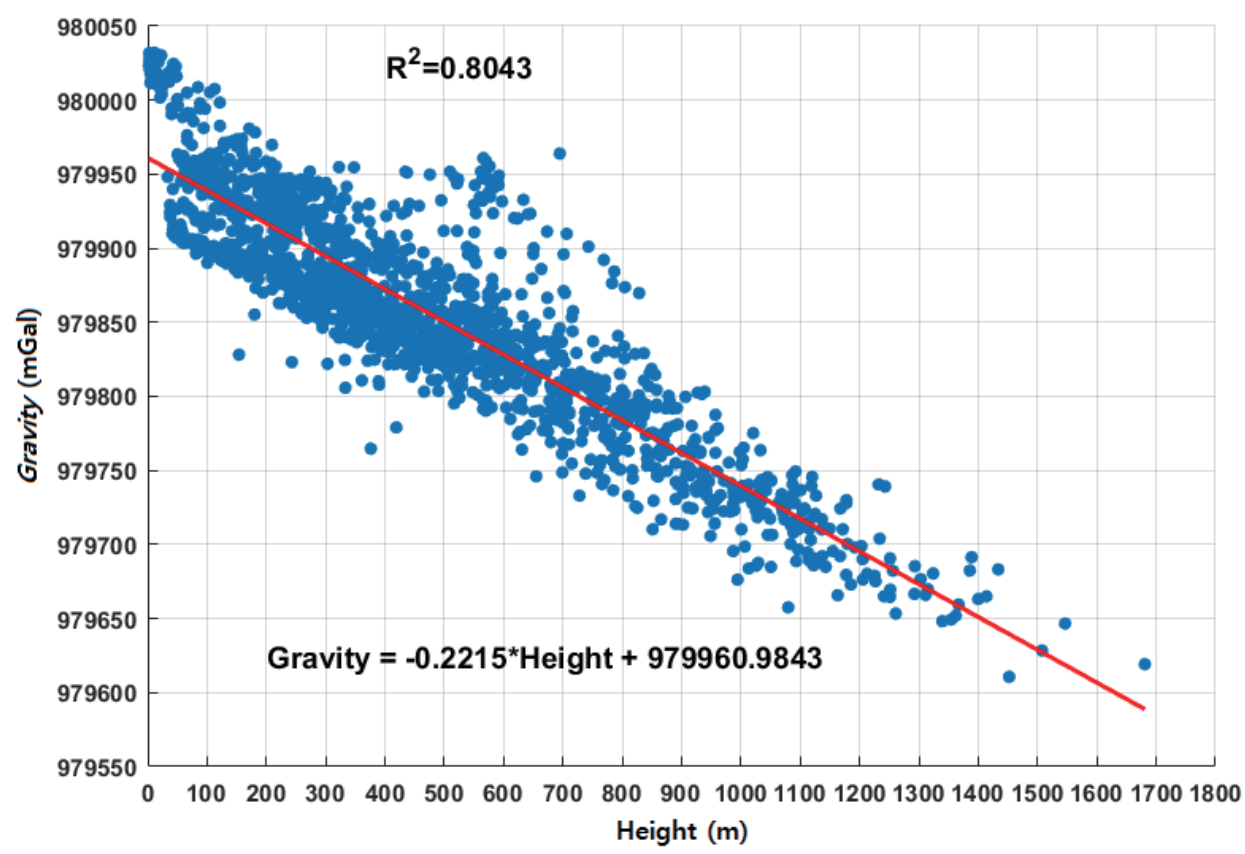

Fig. 4. (Color online) Coefficient of determination $\left(R^{2}\right)$ between height and gravity determined by linear regression analysis.

these estimated gravity values, a 5" GGD of the study area was generated by using a continuous curvature surface gridding algorithm of Generic Mapping Tools (GMT, http://gmt.soest.hawaii. edu) "surface" routine. ${ }^{(20)}$

As shown in Fig. 5, 5" GGD has distributions of 979589.69 mGal (minimum), 979968.13 mGal (maximum), and 979855.75 mGal (mean). In 5" GGD of the study area, it can be seen that the gravity value in the west, where the height is small, is about $300 \mathrm{mGal}$ higher than that in the mountainous area in the east with a large height, except for the sea area around the coast in the upper right area.

For the 5" GGD in Fig. 5, in order to evaluate the accuracy of the GGD compared with the measured gravity data, the gravity values were interpolated to 1844 national control points as shown in Fig. 3. Figure 6 shows the difference between the interpolated gravity from the 5" GGD and the measured gravity. As shown in Table 1, the differences are $-156.70 \mathrm{mGal}$ (minimum), $112.44 \mathrm{mGal}$ (maximum), $-0.09 \mathrm{mGal}$ (mean), and $33.25 \mathrm{mGal}$ (standard deviation). The accuracy according to the resolution change of the GGD was about $33 \mathrm{mGal}$, and there was no significant change. In addition, as shown in Fig. 6 , the north of latitude $38^{\circ}$ of the study area shows a gravity difference of $-80 \mathrm{mGal}$ or higher in the upper left area and $-60 \mathrm{mGal}$ or higher in the upper right area. This is an error caused by the lack of DEM data near the border between North Korea and South Korea.

Figure 7 shows a histogram of the difference between the interpolated gravity from 5" GGD and the measured gravity at 1844 national control points. At 1844 national control points within the study area, the difference in gravity is almost similar to the normal distribution curve based 


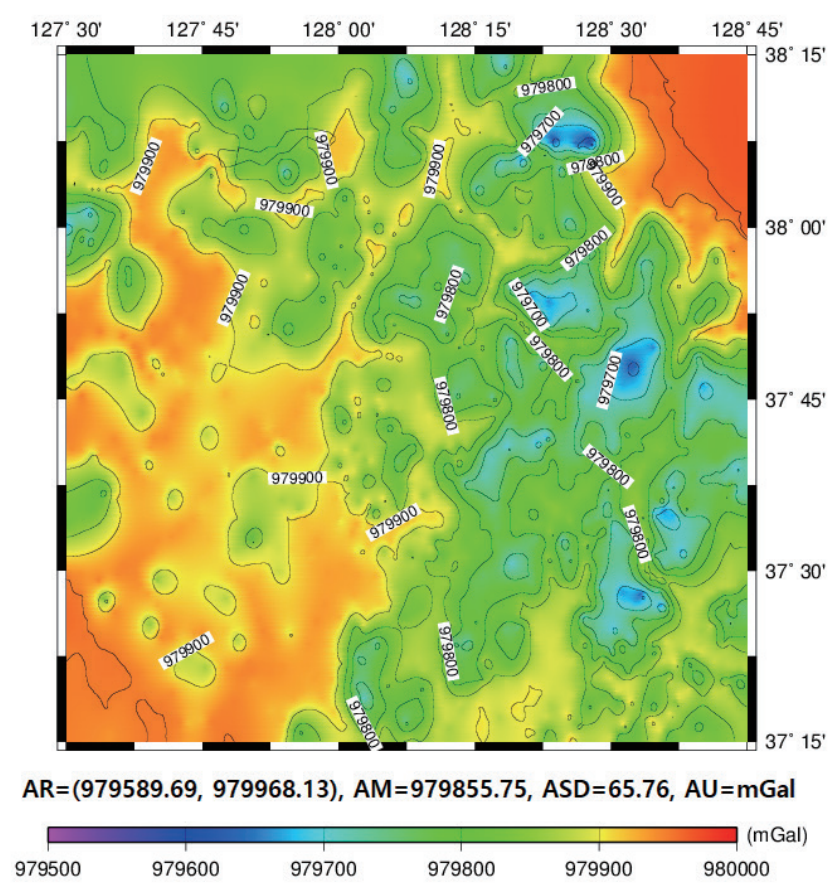

Fig. 5. (Color online) 5" gridded gravity data in the study area. The attributes listed for this and subsequent maps include the amplitude range (AR = minimum and maximum values), amplitude mean (AM), amplitude standard deviation (ASD), and amplitude unit (AU).

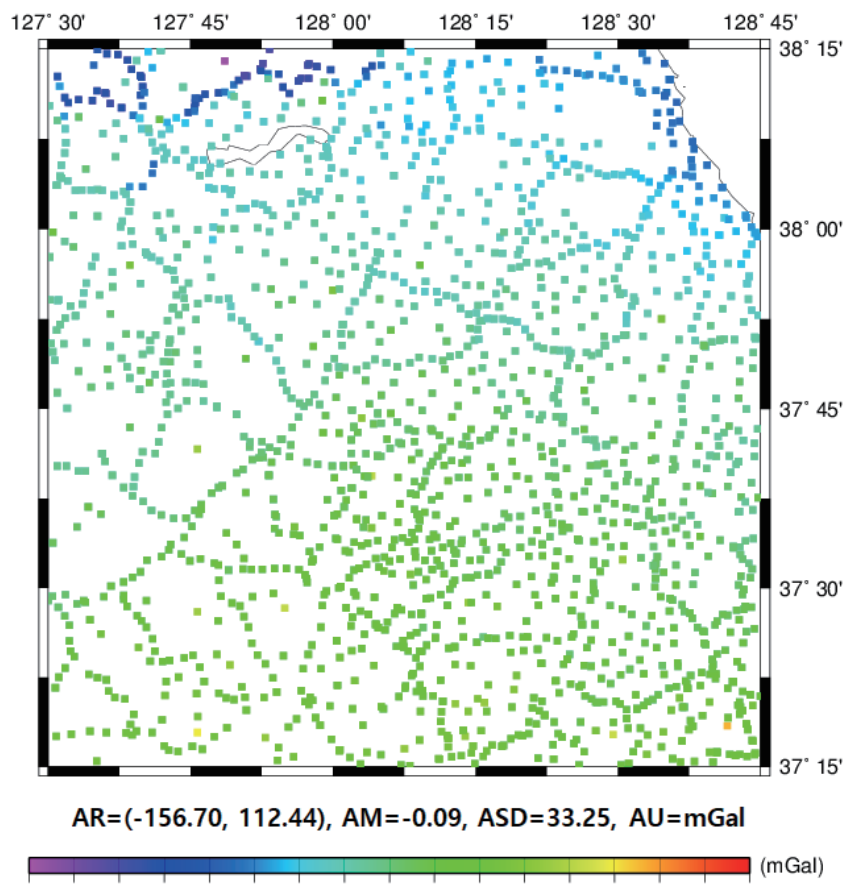

$-160-140-120-100-80-60-40-20 \quad 0 \quad 20 \quad 40 \quad 60 \quad 80 \quad 100120140160$

Fig. 6. (Color online) Gravity differences between the gravity interpolated from the gridded gravity data and the measured gravity at 1844 national control points. 
Table 1

Statistics of differences between the gravity interpolated from the gridded gravity data and the measured gravity at 1844 national control points.

\begin{tabular}{lcccc}
\hline & Min. $(\mathrm{mGal})$ & Max. $(\mathrm{mGal})$ & Mean $(\mathrm{mGal})$ & Std. Dev. $(\mathrm{mGal})$ \\
\hline Difference & -156.70 & 112.44 & -0.09 & 33.25 \\
\hline
\end{tabular}

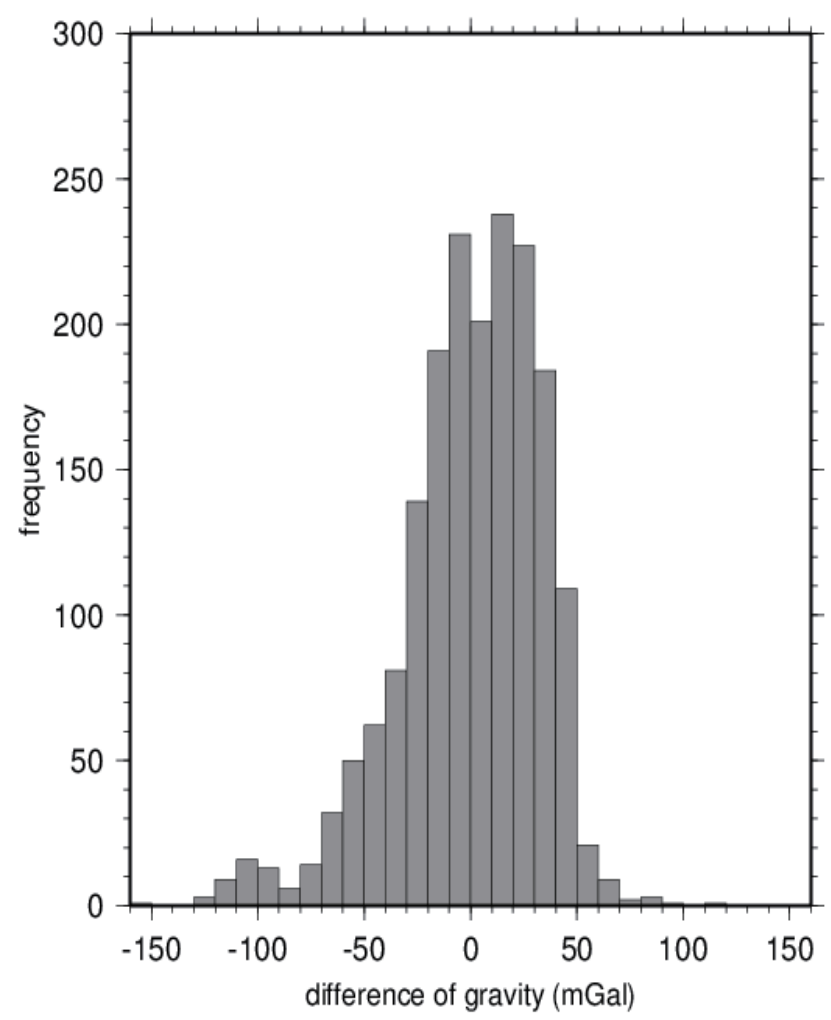

Fig. 7. Histograms of differences between the gravity interpolated from the gridded gravity data and the measured gravity at 1844 national control points.

Table 2

Percentage of differences between the gravity interpolated from the gridded gravity data and the measured gravity at 1,844 national control points.

\begin{tabular}{lcccccc}
\hline & $\leq 10 \mathrm{mGal}$ & $\leq 20 \mathrm{mGal}$ & $\leq 30 \mathrm{mGal}$ & $\leq 40 \mathrm{mGal}$ & $\leq 50 \mathrm{mGal}$ & $\leq 60 \mathrm{mGal}$ \\
\hline Difference & $432(23.4 \%)$ & $861(46.7 \%)$ & $1227(66.5 \%)$ & $1492(80.9 \%)$ & $1663(90.2 \%)$ & $1734(94.0 \%)$ \\
\hline
\end{tabular}

on $0 \mathrm{mGal}$. In addition, the percentage difference between the interpolated gravity from 5" GGD and the measured gravity is shown in Table 2. As shown in Table 2, the measured gravity and the gravity interpolated from GGD among the 1844 national control points show differences within $\pm 40 \mathrm{mGal}$ and $\pm 50 \mathrm{mGal}$ at $80.9 \%$ (1,492 points) and $90.2 \%$ (1,663 points), respectively. In the statistical table shown in Table 1, it was found that 1318 points $(71.5 \%)$ were distributed within the standard deviation $\pm 33.25 \mathrm{mGal}$ of the difference between the gravity interpolated from the GGD and the measured gravity. 


\subsection{Comparison of orthometric corrections}

In this study, orthometric correction using the Heiskanen and Moritz formula of Eq. (3) and cumulative orthometric correction were calculated on two routes (indicated by \#27 and \#12 in Fig. 3) within the study area using the measured gravity at 1844 national control points and the gravity interpolated from 5" GGD generated from the height extracted from the DEM. These results were compared with the orthometric and cumulative orthometric corrections calculated on the two routes using the actual measured gravity. In Fig. 3, the two routes \#27 and \#12 marked with red squares represent the first-order leveling line \#27 and the second-order leveling line \#12 of loop \#9, respectively.

Table 3 shows the measured gravity and the gravity interpolated from 5" GGD at a total of 29 points on the first-order leveling line \#27 with a maximum height of $426.0586 \mathrm{~m}$. The orthometric and cumulative orthometric corrections were calculated by using the measured and

Table 3

Comparisons of gravity, orthometric correction (OC), and cumulative orthometric correction (COC) computed from the measured gravity and gridded gravity along the first-order leveling line \#27.

\begin{tabular}{|c|c|c|c|c|c|c|c|c|c|c|}
\hline \multirow[b]{2}{*}{ No. } & \multirow[b]{2}{*}{$\begin{array}{l}\text { Point } \\
\text { ID }\end{array}$} & \multirow{2}{*}{$\begin{array}{l}\text { Latitude } \\
\text { (degree) }\end{array}$} & \multirow{2}{*}{$\begin{array}{c}\text { Longitude } \\
\text { (degree) }\end{array}$} & \multirow{2}{*}{$\begin{array}{l}\text { Height } \\
\text { (m) }\end{array}$} & \multicolumn{3}{|c|}{ Measured Data } & \multicolumn{3}{|c|}{ Gridded Data } \\
\hline & & & & & $\begin{array}{l}\text { Gravity } \\
\text { (mGal) }\end{array}$ & $\begin{array}{l}\mathrm{OC} \\
(\mathrm{m})\end{array}$ & $\begin{array}{l}\mathrm{COC} \\
(\mathrm{m})\end{array}$ & $\begin{array}{l}\text { Gravity } \\
\text { (mGal) }\end{array}$ & $\begin{array}{l}\mathrm{OC} \\
(\mathrm{m})\end{array}$ & $\begin{array}{l}\mathrm{COC} \\
(\mathrm{m})\end{array}$ \\
\hline 1 & BM16 & 37.49106 & 127.98475 & 122.4464 & 979900.320 & 0.0000 & 0.0000 & 979934.248 & 0.0000 & 0.0000 \\
\hline 2 & $27-01-00$ & 37.50803 & 127.95461 & 152.6516 & 979895.370 & 0.0003 & 0.0003 & 979925.579 & 0.0009 & 0.0009 \\
\hline 3 & U_HC37 & 37.51360 & 127.95350 & 177.9109 & 979897.679 & -0.0008 & -0.0004 & 979919.849 & 0.0006 & 0.0015 \\
\hline 4 & $27-02-00$ & 37.53628 & 127.96231 & 141.7801 & 979901.289 & -0.0001 & -0.0005 & 979928.957 & -0.0010 & 0.0005 \\
\hline 5 & U_HC39 & 37.54014 & 127.96490 & 141.5096 & 979902.191 & -0.0001 & -0.0006 & 979929.315 & 0.0000 & 0.0004 \\
\hline 6 & $27-03-00$ & 37.55108 & 127.95886 & 163.5545 & 979899.185 & 0.0002 & -0.0005 & 979921.957 & 0.0009 & 0.0013 \\
\hline 7 & $27-04-00$ & 37.57364 & 127.94181 & 196.8189 & 979893.422 & 0.0005 & 0.0001 & 979917.586 & 0.0003 & 0.0016 \\
\hline 8 & U_HC36 & 37.57530 & 127.93068 & 218.9748 & 979884.437 & 0.0015 & 0.0016 & 979909.428 & 0.0013 & 0.0029 \\
\hline 9 & $27-04-01$ & 37.57722 & 127.90550 & 264.1510 & 979879.577 & 0.0003 & 0.0018 & 979900.401 & 0.0013 & 0.0042 \\
\hline 10 & U_HC17 & 37.58329 & 127.89741 & 316.9076 & 979870.406 & 0.0014 & 0.0032 & 979887.338 & 0.0025 & 0.0067 \\
\hline 11 & $27-05-00$ & 37.60017 & 127.90008 & 426.0586 & 979851.919 & 0.0035 & 0.0067 & 979866.028 & 0.0046 & 0.0113 \\
\hline 12 & U_HC18 & 37.60282 & 127.89841 & 400.1021 & 979857.285 & -0.0013 & 0.0054 & 979877.523 & -0.0039 & 0.0074 \\
\hline 13 & U_HC19 & 37.62393 & 127.89557 & 266.5401 & 979885.565 & -0.0058 & -0.0004 & 979897.675 & -0.0030 & 0.0044 \\
\hline 14 & $27-07-00$ & 37.65781 & 127.88811 & 170.9155 & 979910.272 & -0.0037 & -0.0041 & 979921.928 & -0.0036 & 0.0008 \\
\hline 15 & U_HC20 & 37.65791 & 127.88677 & 168.5150 & 979910.738 & 0.0000 & -0.0041 & 979923.114 & -0.0002 & 0.0006 \\
\hline 16 & $\mathrm{U}_{-} \mathrm{HC} 05$ & 37.68162 & 127.86997 & 127.8601 & 979925.817 & -0.0018 & -0.0059 & 979931.421 & -0.0007 & -0.0001 \\
\hline 17 & $27-08-00$ & 37.69747 & 127.85364 & 128.0825 & 979932.021 & -0.0008 & -0.0067 & 979932.644 & -0.0002 & -0.0003 \\
\hline 18 & U0170 & 37.70401 & 127.85425 & 131.8996 & 979932.363 & -0.0001 & -0.0068 & 979931.204 & 0.0001 & -0.0001 \\
\hline 19 & $27-09-00$ & 37.71186 & 127.84350 & 140.2609 & 979932.307 & -0.0001 & -0.0069 & 979930.226 & 0.0000 & -0.0001 \\
\hline 20 & U_HC04 & 37.74214 & 127.83023 & 212.5436 & 979920.798 & 0.0010 & -0.0059 & 979914.612 & 0.0017 & 0.0016 \\
\hline 21 & $27-10-00$ & 37.74303 & 127.83117 & 207.2045 & 979922.005 & -0.0002 & -0.0061 & 979915.005 & 0.0000 & 0.0016 \\
\hline 22 & $27-11-00$ & 37.75419 & 127.79586 & 163.0144 & 979932.088 & -0.0012 & -0.0072 & 979924.051 & -0.0010 & 0.0006 \\
\hline 23 & U0205 & 37.75201 & 127.79613 & 161.5999 & 979931.831 & 0.0001 & -0.0072 & 979923.455 & 0.0001 & 0.0007 \\
\hline 24 & $27-12-00$ & 37.76081 & 127.77258 & 225.7640 & 979919.566 & 0.0013 & -0.0058 & 979908.105 & 0.0020 & 0.0027 \\
\hline 25 & $27-13-00$ & 37.78619 & 127.75847 & 198.7964 & 979925.175 & -0.0007 & -0.0066 & 979914.032 & -0.0008 & 0.0019 \\
\hline 26 & $27-14-00$ & 37.81286 & 127.76306 & 274.9533 & 979906.028 & 0.0031 & -0.0035 & 979899.900 & 0.0019 & 0.0038 \\
\hline 27 & $27-15-00$ & 37.83194 & 127.76194 & 116.5752 & 979937.582 & -0.0036 & -0.0071 & 979934.591 & -0.0042 & -0.0005 \\
\hline 28 & U_CC08 & 37.85885 & 127.73329 & 81.2474 & 979946.499 & -0.0006 & -0.0077 & 979941.894 & -0.0004 & -0.0009 \\
\hline 29 & BM19 & 37.88117 & 127.72925 & 96.9381 & 979945.632 & 0.0000 & -0.0077 & 979940.391 & 0.0000 & -0.0009 \\
\hline
\end{tabular}


interpolated gravity, respectively. When using the measured gravity, the minimum and maximum orthometric corrections for each section are $-0.0058 \mathrm{~m}$ and $0.0035 \mathrm{~m}$, respectively, and the cumulative orthometric correction is $-0.0077 \mathrm{~m}$ at the 29th point (BM19). In addition, when using the gravity interpolated from 5" GGD, the minimum and maximum orthometric corrections for each section are $-0.0042 \mathrm{~m}$ and $0.0046 \mathrm{~m}$, respectively, and the cumulative orthometric correction is $-0.0009 \mathrm{~m}$ at the 29 th point (BM19).

Table 4 shows the measured gravity at a total of 33 points of the second-order leveling line \#12 of loop \#9 with a maximum height of $1011.2616 \mathrm{~m}$ and the gravity interpolated from 5" GGD. The orthometric and cumulative orthometric corrections were calculated by using the measured gravity and the gravity interpolated from 5" GGD, respectively. When the measured gravity is used, the minimum and maximum orthometric corrections for each section are

Table 4

Comparisons of gravity, orthometric correction (OC), and cumulative orthometric correction (COC) computed from the measured gravity and gridded gravity along the second-order leveling line \#12 of loop \#9.

\begin{tabular}{|c|c|c|c|c|c|c|c|c|c|c|}
\hline \multirow[b]{2}{*}{ No. } & \multirow{2}{*}{$\begin{array}{l}\text { Point } \\
\text { ID }\end{array}$} & \multirow{2}{*}{$\begin{array}{l}\text { Latitude } \\
\text { (degree) }\end{array}$} & \multirow{2}{*}{$\begin{array}{c}\text { Longitude } \\
\text { (degree) }\end{array}$} & \multirow{2}{*}{$\begin{array}{l}\text { Height } \\
\text { (m) }\end{array}$} & \multicolumn{3}{|c|}{ Measured Data } & \multicolumn{3}{|c|}{ Gridded Data } \\
\hline & & & & & $\begin{array}{l}\text { Gravity } \\
\text { (mGal) }\end{array}$ & $\begin{array}{l}\mathrm{OC} \\
(\mathrm{m})\end{array}$ & $\begin{array}{c}\mathrm{COC} \\
(\mathrm{m})\end{array}$ & $\begin{array}{l}\text { Gravity } \\
\text { (mGal) }\end{array}$ & $\begin{array}{l}\mathrm{OC} \\
(\mathrm{m})\end{array}$ & $\begin{array}{l}\mathrm{COC} \\
(\mathrm{m})\end{array}$ \\
\hline 1 & 09-05-00-00 & $3 \% . / 1$ & & & 979836.196 & 0.0000 & & 979830.827 & 0.0000 & 0.0000 \\
\hline 2 & & & & & 979835.911 & 0.0006 & 0.0006 & 979831.329 & 0.0001 & 0.0001 \\
\hline 3 & $09-05-12-02$ & & & & 979834.998 & 0.0009 & 0.0015 & 979826.837 & 0.0030 & 0.0031 \\
\hline 4 & $09-05-12-03$ & 37.81031 & 128.41078 & 558.4924 & 979843.343 & -0.0042 & -0.0027 & 979834.623 & -0.0039 & -0.0008 \\
\hline 5 & $09-05-12-04$ & 37.82083 & 128.41486 & 528.8628 & 979852.761 & -0.0038 & -0.0065 & 979843.040 & -0.0033 & -0.0041 \\
\hline 6 & $09-05-12-05$ & 37.82814 & 128.41758 & 536.1185 & 979850.781 & 0.0007 & -0.0058 & 979839.879 & 0.0014 & -0.0027 \\
\hline 7 & $09-05-12-06$ & 37.82847 & 128.44439 & 545.0409 & 979847.689 & 0.0013 & -0.0045 & 979837.727 & 0.0008 & \\
\hline 8 & & & & & 979846.256 & 0.0005 & & 79839.068 & -0.0011 & \\
\hline 9 & & & & & & & & & & \\
\hline 10 & & & & & 35.239 & 0.0019 & -0.0001 & 5.633 & 0.0023 & 0.0024 \\
\hline 11 & $09-05-12-10$ & & & & 979830.862 & 0.0015 & 0.0014 & 979815.998 & 0.0048 & 0.0072 \\
\hline 12 & U_YK12 & 37.85253 & 128.51008 & 720.1167 & 979814.687 & 0.0056 & 0.0070 & 979804.308 & 0.0025 & 0.0097 \\
\hline 13 & $09-05-12-11$ & & & 756. & 979807.600 & 0.0030 & 0.0 & 979802.025 & -0.0006 & .0091 \\
\hline 14 & & & & & & & & & & \\
\hline 15 & & & & & & & & & & \\
\hline 16 & & & & & & & & & & \\
\hline 17 & & & & & & & & & & \\
\hline 18 & & & & & & & & & & \\
\hline 19 & $09-05-12-17$ & & & & & & & & -0.0080 & \\
\hline 20 & U_YK11 & 37.90944 & 128.50344 & 358.8456 & 979890.687 & -0.0035 & -0.0216 & 979876.554 & -0.0067 & -0.0136 \\
\hline 21 & $09-\overline{0} 5-12-18$ & & & & 979896.769 & -0.0013 & -0.0 & 86.125 & -0.0026 & -0.0162 \\
\hline 22 & & & & & & -0.0029 & -0.0258 & & -0.0020 & \\
\hline 23 & $09-05-12-20$ & & & & 979926.502 & -0.0028 & -0.0286 & 979906.369 & -0.0011 & -0.0 \\
\hline 24 & & & & & & -0.0020 & -0.0306 & & -0.0017 & \\
\hline 25 & & & & & & & & & -0.0002 & \\
\hline 26 & $05-03-12-2 z$ & & & & +5.065 & -0.0008 & & & -0.0003 & \\
\hline 27 & $09-05-12-23$ & 37.98861 & 128.53006 & 148.9204 & 979955.879 & -0.0015 & -0.0328 & 979926.033 & -0.0005 & -0.0220 \\
\hline 28 & $09-05-12-24$ & 38.00219 & 128.53811 & 156.8521 & 979958.598 & -0.0005 & -0.0333 & 979920.812 & 0.0007 & -0.0213 \\
\hline 29 & $09-05-12-25$ & 38.01856 & 128.54375 & 175.7267 & 979959.892 & -0.0005 & -0.0338 & 979924.154 & -0.0008 & -0.0221 \\
\hline 30 & $09-05-12-26$ & 38.02850 & 128.54900 & 138.0162 & 979970.131 & -0.0011 & -0.0349 & 979926.581 & 0.0001 & -0.0220 \\
\hline 31 & $09-05-12-27$ & 38.04181 & 128.55758 & 63.6322 & 979988.572 & -0.0013 & -0.0362 & 979947.057 & -0.0015 & -0.0235 \\
\hline 32 & $09-05-12-28$ & 38.05019 & 128.57058 & & 979985.706 & 0.0000 & -0.0362 & 979943.926 & 0.0001 & -0.0234 \\
\hline 33 & 09-08-00-00 & 38.06039 & 128.57453 & 38.3605 & 980000.754 & -0.0007 & -0.0369 & 979949.588 & -0.0001 & -0.0235 \\
\hline
\end{tabular}


$-0.0182 \mathrm{~m}$ and $0.0135 \mathrm{~m}$, respectively, and the cumulative orthometric correction is $-0.0369 \mathrm{~m}$ at the 33rd point (09-08-00-00). In addition, when using the gravity interpolated from 5" GGD, the minimum and maximum orthometric corrections for each section are $-0.0186 \mathrm{~m}$ and $0.0327 \mathrm{~m}$, respectively, and the cumulative orthometric correction is $-0.0235 \mathrm{~m}$ at the $33 \mathrm{rd}$ point (09-0800-00). The difference of COC of $1.34 \mathrm{~cm}$ at the $33 \mathrm{rd}$ point was attributable to the underestimated gravity interpolated from 5" GGD in the mountainous areas, as shown in Fig. 8(d).

On the basis of the results shown in Tables 3 and 4, it was found that when using the measured gravity at 29 points in first-order leveling line \#27 with a small height and the gravity interpolated from 5" GGD, the orthometric and cumulative orthometric corrections were small. When using the measured gravity and gravity interpolated from 5" GGD for a total of 33 points on the second-order leveling line \#12 of loop \#9 with a relatively large height, the orthometric and cumulative orthometric corrections were found to be larger than those of the relatively small height zone.

Figure 8 shows the height at each station on the first-order leveling line \#27 and second-order leveling line $\# 12$ of loop \#9, the measured gravity and the gravity interpolated from the 5" GGD, and the orthometric and cumulative orthometric corrections for each section calculated by using the measured gravity and interpolated gravity from the 5" GGD. Table 5 shows the statistics on the difference between the measured gravity in the first-order leveling line \#27 and secondorder leveling line \#12 of loop \#9, and the gravity interpolated from 5" GGD, and the difference between orthometric and cumulative orthometric corrections was calculated by using the gravity and the gravity interpolated from 5" GGD, as shown in Fig. 8.

The difference between the measured gravity and the gravity interpolated from 5" GGD at the stations on the first-order leveling line \#27 and second-order leveling line \#12 of loop \#9, and the standard deviation of the difference are $14.577 \mathrm{mGal}$ and $12.651 \mathrm{mGal}$, respectively. This indicates that the standard deviation of the gravity difference for a total of 1844 national control points within the study area is smaller than $33.25 \mathrm{mGal}$. On the first-order leveling line \#27 and second-order leveling line \#12 of loop \#9, the mean orthometric correction difference between the two points for each section was about $0.4 \mathrm{~mm}$, and the standard deviation was about $4 \mathrm{~mm}$. The mean cumulative orthometric correction difference for each section is about $7.5 \mathrm{~mm}$, and the standard deviation is about $5 \mathrm{~mm}$. However, as shown in Table 5, the maximum differences of $\mathrm{OC}$ of $1.92 \mathrm{~cm}$ and $\mathrm{COC}$ of $1.84 \mathrm{~cm}$ on the second-order leveling line \#12 of loop \#9 were attributable to the underestimated gravity interpolated from 5" GGD in the mountainous areas, as shown in Fig. 8(d).

These results show that in the first-order leveling line \#27 with a small height and secondorder leveling line \#12 of loop \#9 with a large height, there is no significant difference between the orthometric and cumulative orthometric corrections calculated using the gravity interpolated from the GGD generated from the linear relationship between height and gravity, and the orthometric and cumulative orthometric corrections calculated from the actual measured gravity. 


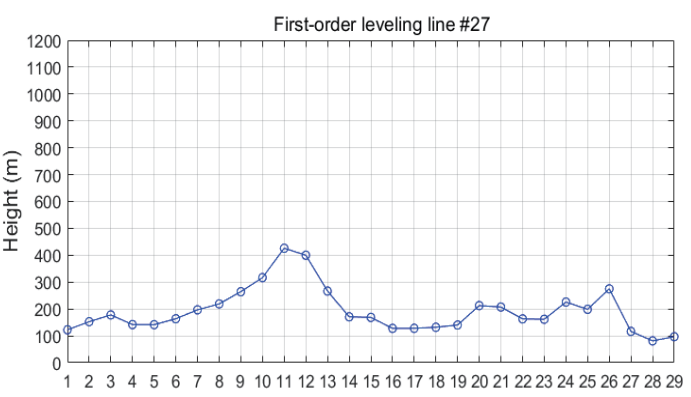

(a)

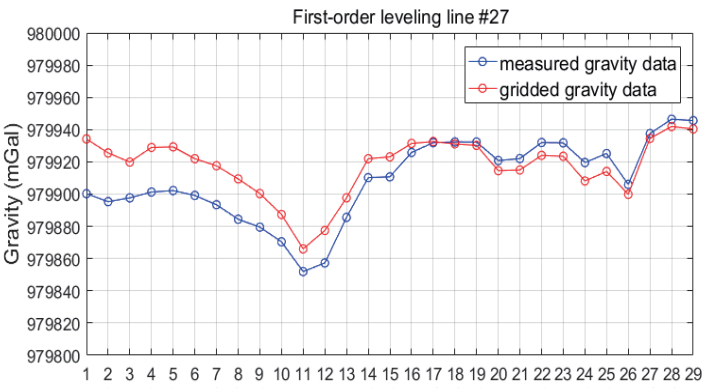

(c)

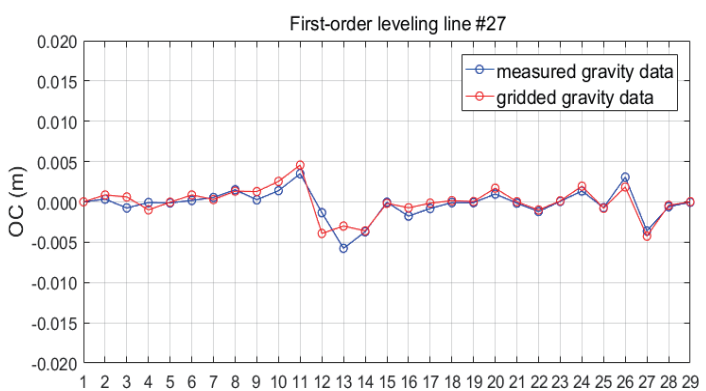

(e)

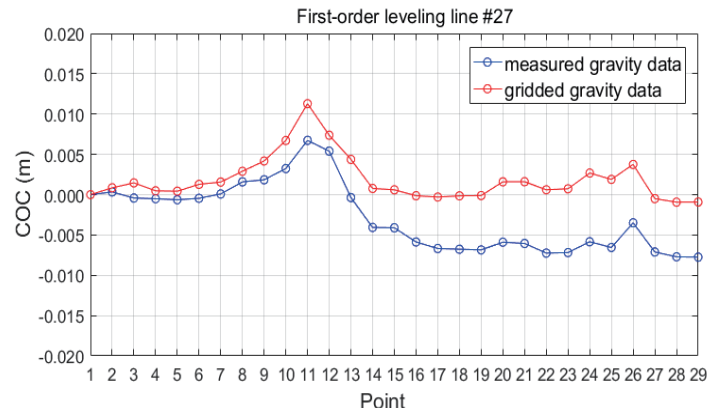

(g)

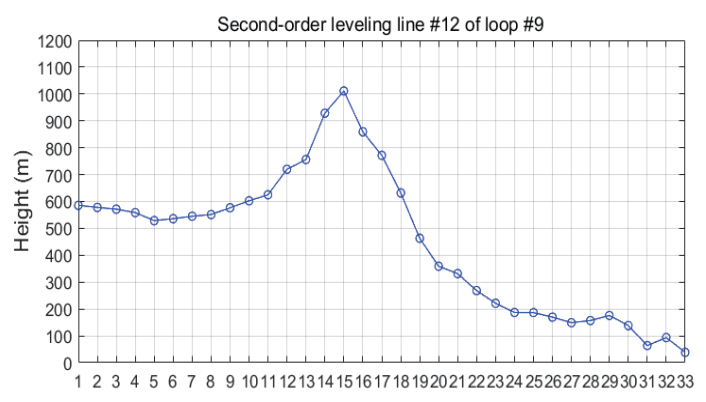

(b)

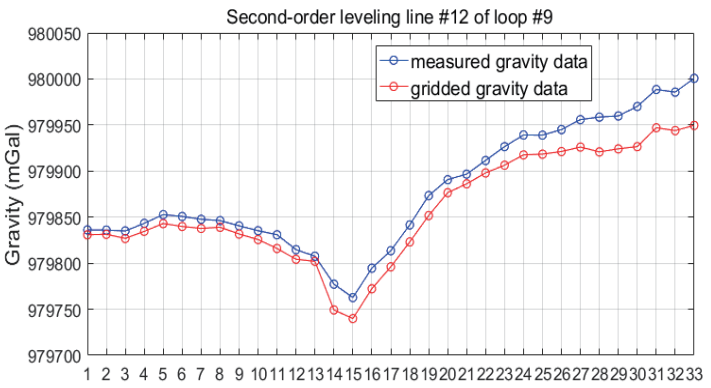

(d)

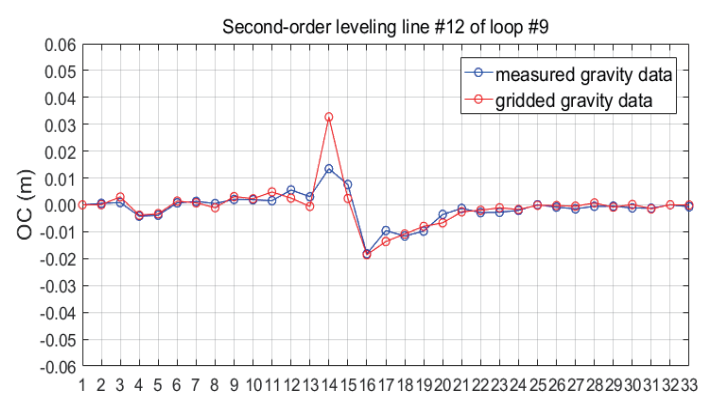

$(\mathrm{f})$

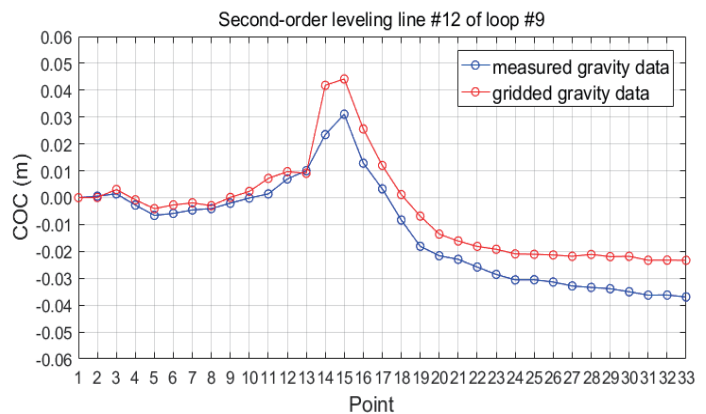

(h)

Fig. 8. (Color online) Comparisons of height, gravity, orthometric correction (OC), and cumulative orthometric correction (COC) from the measured gravity and gridded gravity in the first-order leveling line \#27 (a, c, e, and g) and the second-order leveling line \#12 of loop \#9 (b, d, f, and h). 
Table 5

Statistics of differences of gravity, orthometric correction (OC), and cumulative orthometric correction (COC) between the measured gravity and the gridded gravity along the first-order leveling line \#27 and the secondorder leveling line \#12 of loop \#9.

\begin{tabular}{lcrrrc}
\hline & Name of route & Min. & Max. & Mean & Std. Dev. \\
\hline \multirow{2}{*}{ Gravity (mGal) } & First-order leveling line \#27 & -11.461 & 33.928 & 8.727 & 14.577 \\
& Second-order leveling line \#12 of loop \#9 & -51.166 & -4.582 & -19.716 & 12.651 \\
\hline \multirow{2}{*}{ OC (m) } & First-order leveling line \#27 & -0.0026 & 0.0028 & 0.0002 & 0.0010 \\
& Second-order leveling line \#12 of loop \#9 & -0.0052 & 0.0192 & 0.0004 & 0.0039 \\
\hline \multirow{2}{*}{ COC (m) } & First-order leveling line \#27 & 0.0000 & 0.0085 & 0.0047 & 0.0028 \\
& Second-order leveling line \#12 of loop \#9 & -0.0010 & 0.0184 & 0.0075 & 0.0051 \\
\hline
\end{tabular}

\section{Conclusions}

In this study, the gridded gravity data were generated by using the high correlation and linear relationship between the height and gravity extracted from the high-resolution DEM in the areas where the national control points where gravity was measured are not densely distributed. In addition, its accuracy was evaluated by comparison with measured gravity at 1844 national control points. The following conclusions were derived.

Height data extracted from DEM are characterized by a high linear correlation with the measured gravity. In this study, the gravity was calculated by using the linear regression equation derived from the linear correlation between the measured gravity and the height extracted from a high-resolution DEM. The coefficient of determination $R^{2}$ between the two data through the linear regression analysis of the measured gravity at 1844 national control points and the height interpolated from the 5 " gridded height data is 0.8043 , thereby indicating a high correlation between the two data. By using this feature, GGD was generated in an area where the national control points where gravity was measured are not densely distributed. Comparison of GGD with the measured gravity at national control points revealed that the accuracy was about $33 \mathrm{mGal}$.

Calculation of the orthometric and cumulative orthometric corrections for each section along the leveling line using the interpolated gravity from the GGD revealed that the difference between the results from the interpolated gravity and the measured gravity is very small. It can be suggested that, by using the interpolated gravity at the points where there are no gravity data, the orthometric correction can be identified effectively without measuring the gravity.

If the national control points for observing gravity are more densely distributed, it is expected that the accuracy of the gravity interpolated from GGD can be further improved from the linear correlation with the height data extracted from the high-resolution DEM.

\section{Acknowledgments}

This work was supported by the National Research Foundation of Korea (NRF) grant funded by the Korean government (MSIT) (NRF-2019R1C1C1005590). 


\section{References}

1 W. A. Heiskanen and H. Moritz: Physical Geodesy (W.H. Freeman and Company, 1967) Chap.4.

2 P. Vaníček and E. J. Krakiwsky: Geodesy the Concepts (Elsevier, 1986) 2nd ed.

3 C. K. Lee, Y. C. Suh, B. N. Jeon, and C. H. Song: J. Korean Soc. Surv. Geod. Photogram. Cartogr. 26 (2008) 17.

4 M. M. Nassar: UNB Technical Report No. 41 (1977).

5 G. L. Strang van Hees: Zeitschrift fur Vermessungwesen 11 (1992) 727.

6 D. Dong: Formulas for Surveying and Mapping (Military Survey Book Company, 1990) p.74.

7 C. Hwang and Y.-S. Hsiao: J. Geod. 77 (2003) 279. https://doi.org/10.1007/s00190-003-0325-6

8 S.-P. Kao, R. Hsu, and F.-S. Ning: Geom. Res. Aus. 72 (2000) 43.

9 M. L. Denis and W. E. Featherstone: Proc. GG 3rd Meeting of the IGGC 2002, Ed. I. N. Tziavos (IAG, Thessaloniki, 2002) 389-394.

10 R. Barzaghi, B, Betti, D. Carrion, G. Gentile, R. Maseroli, and F. Sacerdote: Appl. Geom. 6 (2014) 17. https:// doi.org/10.1007/s12518-013-0121-9

11 R. Tenzer, P. Vaníček, M. Santos, W. E. Fatherstone, and M. Kuhn: J. Geod. 79 (2005) 82. https://doi. org/10.1007/s00190-005-0445-2

12 P. A. Odera and Y. Fukuda: Earth Planets Space 67 (2015) 27. https://doi.org/10.1186/s40623-015-0194-2

13 J. O. Odumosu, O. G. Ajayi, F. F. Idowu, and E. A. Adesina: J. King Saud Univ. Eng. Sci. 30 (2018) 46. http:// dx.doi.org/10.1016/j.jksues.2015.09.002

14 H. S. Yun and J. M. Cho: J. Korean Soc. Surv. Geod. Photogram. Cartogr. 22 (2004) 117.

15 Y. J. Lee, Y. S. Choi, J. H. Kwon, and J. S. Lee: J. Korean Soc. Surv. Geod. Photogram. Cartogr. 28 (2010) 99.

16 K. S. Choi and J. M. Lee: J. Korean Earth Sci. Soc. 18 (1997) 522.

17 C. Y. Kim and S. B. Lee: J. Korean Soc. Surv. Geod. Photogram. Cartogr. 29 (2011) 319. https://doi.org/10.7848/ ksgpc.2011.29.3.319

18 S. B. Lee, S.-C. Auh, and C.-H. Lee: Proc. Korean Soc. Geospatial Inf. Sci. (KSGIS, 2015) 95.

19 S. B. Lee and S.-C. Auh: J. Cadastre Land Inf. 48 (2018) 99. http://doi.org/10.22640/1xsiri.2018.48.2.99

20 P. Wessel, W. H. F. Smith, R. Scharroo, J. Luis, and F. Wobbe: EOS Trans. Am. Geophys. Union 94 (2013) 409.

\section{About the Authors}

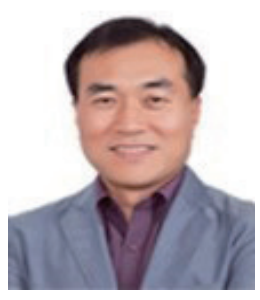

Hong Sool Lee received his B.S. and M.S. degrees from Sungkyunkwan University, Korea in 1991 and 1994, respectively. He is currently a Ph.D. candidate at Sungkyunkwan University. Since 1993, he has been working in photogrammetry and mapping, ICT, and spatial information construction. His research interests are in geodesy, GIS, and smart city. (ikaros0306@naver. com)

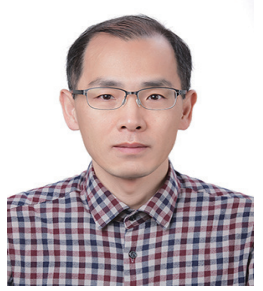

Kwang Bae Kim received his B.S. and M.S. degrees from Sungkyunkwan University, Korea in 1993 and 1996, respectively. He also received his M.S. degree from Ohio State University, USA in 2001 and Ph.D. degree from Kunsan National University, Korea in 2016, respectively. Since 2016, he has been a research professor at Sungkyunkwan University. His research interests are in satellite geodesy and bathymetry mapping. (kbkim929@skku.edu)

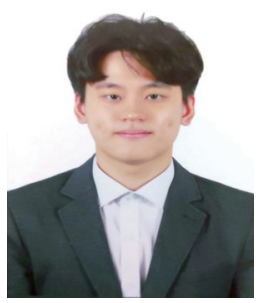

Chang Uk Woo received his B.S. degree from Sungkyunkwan University, Korea in 2021. He is currently an M.S. student of the Department of Civil, Architectural, and Environmental System Engineering at Sungkyunkwan University. His research interests are in geodesy. (dnr8874@skku.edu) 


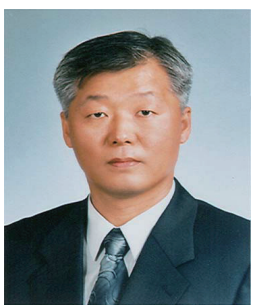

Hong Sik Yun received his B.S. and M.S. degrees from Sungkyunkwan University, Korea in 1984 and 1987, respectively. He received his Ph.D. degree from the Technical University of Budapest, Hungary in 1995. Since 1999, he has been a professor at Sungkyunkwan University. His research interests are in satellite geodesy, GNSS positioning, and geoid modeling. (yoonhs@skku.edu) 